\title{
Newest Diabetes-Related Technologies for Pediatric Type 1 Diabetes and Its Impact on Routine Care: a Narrative Synthesis of the Literature
}

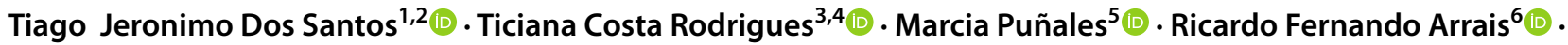 \\ Cristiane Kopacek ${ }^{7}$ (1)
}

Accepted: 4 August 2021 / Published online: 20 August 2021

(c) The Author(s), under exclusive licence to Springer Science+Business Media, LLC, part of Springer Nature 2021

\begin{abstract}
Purpose of Review This review aims to address the actual state of the most advanced diabetes devices, as follows: continuous subcutaneous insulin infusions (CSII), continuous glucose monitoring systems (CGM), hybrid-closed loop (HCL) systems, and "Do-it-yourself" Artificial Pancreas Systems (DIYAPS) in children, adolescents, and young adults. This review has also the objective to assess the use of telemedicine for diabetes care across three different areas: education, social media, and daily care.

Recent Findings Recent advances in diabetes technology after integration of CSII with CGM have increased the popularity of this treatment modality in pediatric age and shifted the standard diabetes management in many countries. We found an impressive transition from the use of CSII and/or CGM only to integrative devices with automated delivery systems. Although much has changed over the past 5 years, including a pandemic period that precipitated a broader use of telemedicine in diabetes care, some advances in technology may still be an additional burden of care for providers, patients, and caregivers. The extent of a higher rate of "auto-mode" use in diabetes devices while using the HCL/DIYAPS is essential to reduce the burden of diabetes treatment.

Summary More studies including higher-risk populations are needed, and efforts should be taken to ensure proper access to cost-effective advanced technology on diabetes care.
\end{abstract}

Keywords Type 1 diabetes $\cdot$ Insulin pump $\cdot$ Continuous glucose monitors $\cdot$ Closed-loop · Artificial pancreas $\cdot$ Telemedicine

Tiago Jeronimo dos Santos, Ticiana Costa Rodrigues, Marcia Khaled Puñales, Ricardo Fernando Arrais, and Cristiane Kopacek contributed equally for the review.

Tiago Jeronimo Dos Santos

tiagojer@gmail.com

1 Pediatrics Unit, Vithas Almería, Instituto Hispalense de Pediatría, Almería Andalusia, Spain

2 Department of Preventive Medicine and Public Health, School of Medicine, Universidad Autónoma de Madrid/IdiPAZ, Madrid, Spain

3 Post Graduate Program in Medical Sciences Endocrinology, Universidade Federal Do Rio Grande Do Sul, Endocrine Division, Hospital de Clínicas de Porto Alegre, Porto Alegre, Rio Grande Do Sul, Brazil

\section{Introduction}

The year 2021 marks the one-hundredth anniversary of the discovery and development of insulin. A tremendous evolution has been observed across the past few years and it is well-known and established that the continuous subcutaneous insulin infusions (CSII) appear to be effective and

4 Diabetes Division, Hospital Moinhos de Vento, Porto Alegre, Rio Grande Do Sul, Brazil

5 Institute for Children with Diabetes, Pediatric Endocrinology Unit, Hospital Nossa Senhora da Conceição, Porto Alegre, Rio Grande Do Sul, Brazil

6 Department of Pediatrics, Pediatric Endocrinology Unit, Federal University of Rio Grande Do Norte, Natal, Rio Grande do Norte, Brazil

7 Department of Pediatrics, Post Graduate Program in Pediatrics, Federal University of Health Sciences of Porto Alegre, Porto Alegre, Rio Grande do Sul, Brazil 
safe in people with type 1 diabetes (T1D) regardless of age besides offering flexible management of diabetes [1]. With the overall uptake of the continuous glucose monitoring (CGM) systems, children with diabetes (CWD) benefited from fewer episodes of severe hypoglycemia, reduced number of painful fingersticks, and remote monitoring features of the latest system [2]. Recent advances in diabetes technology after integration of the CSII with CGMs have increased the popularity of this treatment modality and become standard diabetes management in many countries and almost ideal for pediatric age and bringing more peacefulness to the families of CWD [3]. The integration between the insulin delivery and glucose meters came with the sensor-augmented pump (SAP) systems, although potential beneficial effects were counter steered by low sensor use [4]. These pumps especially worked on the prevention of hypoglycemic events by shutting down insulin delivering and paved the way to the development of the automated insulin delivery systems, the so-called "artificial pancreas." The first advanced product in that direction was the MiniMed 670G (Medtronic Diabetes, Northridge, CA, USA) which received the Food and Drug Administration (FDA) approval in September 2016 [5]. The hybrid closed-loop (HCL) insulin delivery when compared with SAP showed an improvement of glucose control while reducing the risk of hypoglycemia across pediatric patients with suboptimally controlled type 1 diabetes [6]. To date, there are few commercial closed-loop systems available in most high-income countries. Firstly introduced, the Medtronic 670G system showed from a clinical trial that the HCL system was safe for use in people 14 years of age and older with type 1 diabetes with no serious adverse events, such as diabetic ketoacidosis (DKA) or severe hypoglycemia (very low glucose levels) reported during the study [7]. Then, Tandem Control IQ system (Tandem Inc, USA) was also approved after the closed-loop system led to a greater percentage of time that the glucose level was in a target range, with less hyperglycemia and hypoglycemia, and better glycated hemoglobin (HbA1c) levels than a sensor-augmented pump. More recently the introduction of the advanced HCL MiniMed 780G system (Medtronic Diabetes, Northridge, Ca, USA) in adolescents allowed well-controlled patients with T1D to rapidly increase their time in range (TIR), without increasing hypoglycemia frequency [8]. However, just before HCL systems became commercially available, "DoIt-Yourself" artificial pancreas systems (DIYAPS) were developed by individuals with a personal interest in automating insulin delivery with the motto \#wearenotwaiting. Although they are still unlicensed products, and users must take total responsibility for associated risks with their use, they report improvements in HbA1c and TIR, and reduced burden of diabetes [9].
The broader use of the newest diabetes technologies made intensive treatment easier to achieve as diabetes management steps forward to be more patient centered. Apart from technological advances and greater patient satisfaction, and although insulin remains the mainstay of diabetes treatment, results are only better when diabetes care becomes primarily patient-dependent or, in the case of young children, the family assumes this management supported by the multidisciplinary team. Given the fast emergence of innovations in glucose monitoring and insulin delivery, the burden of selfcare has reduced in a manner that improved outcomes [10].

Lately, the beneficial impact of telemedicine and telehealth resources for continuous care in dealing with noncommunicable diseases, which includes diabetes, is an undisputable benefit, especially in countries with large distances and socioeconomic inequalities [11].

This narrative synthesis review aimed to address the actual state of CSII, CGM systems, HCL systems, including DIYAPS in children, adolescents, and young adults. Also, we reviewed telemedicine and telehealth for diabetes care on main results and achievements on this ever-expanding ground of knowledge. To better describe terminologies in diabetes-related technology, we will use acronyms detailed in Table 1.

\section{Methods}

This review was performed according to the Preferred Reporting Items for Systematic Reviews and Meta-Analysis (PRISMA) [14]. We conducted a bibliographic search in Medline (PubMed database) to identify all articles published with defined Boolean search terms (Supplementary Content) from January 2016 to March of 2021. No language restriction was set. We also hand-searched for additional references in previous reviews.

We selected randomized controlled trials and observational studies comprising real-world data that presented glycemic and/or patient-related outcomes after using CSII, CGM system, automated, and integrated insulin infusion devices with glucose monitorization (closed-loop systems). We also included studies that applied telemedicine and telehealth into diabetes clinical practice. For these, we also considered data assessed from surveys. To better systematically present data, studies on telemedicine and telehealth were divided into three groups: education, social media, and daily routine care.

Glycemic outcomes were assessed from $\mathrm{HbA1c}$, severe hypoglycemic ( $\mathrm{SH}$ ) episodes, diabetic ketoacidosis (DKA) events, and the percentage of time that the glucose level was in the target (TIR), below (TBR) and above the range (TAR) of 70 to $180 \mathrm{mg} / \mathrm{dL}$ ( 3.9 to $10.0 \mathrm{mmol} / \mathrm{L}$ ) respectively and patient-reported outcomes were assessed from 
Table 1 Terminologies of the newest diabetes-related technological devices

\begin{tabular}{|c|c|c|}
\hline Diabetes-related technological devices & Acronyms & Description \\
\hline Continuous subcutaneous insulin infusion & CSII & $\begin{array}{l}\text { Devices that continuously deliver basal insulin supply and mealtime or } \\
\text { correction boluses whenever needed, turning it into the most physiological } \\
\text { way to imitate insulin maintenance [3] }\end{array}$ \\
\hline Real-time continuous glucose monitoring system & rt-CGM & $\begin{array}{l}\text { These devices measure interstitial glucose concentrations subcutaneously at } \\
\text { 5-to-15-min intervals utilizing enzyme-tipped electrodes or fluorescence } \\
\text { technology [2] }\end{array}$ \\
\hline Flash glucose monitoring system & FGM & $\begin{array}{l}\text { Differently from rt-CGM, the FGM does not automatically display glucose } \\
\text { readings at regular intervals, but report glucose levels only when the user } \\
\text { scans the sensor by holding a reader, or a cell phone, close to the sensor. } \\
\text { An advantage is that they are factory calibrated, thus eliminating the need } \\
\text { for recalibration, increase ease of use, and economic feasibility [2] }\end{array}$ \\
\hline Sensor-augmented pump & SAP & $\begin{array}{l}\text { They are the combination of CSII with rt-CGM measurement and offer } \\
\text { by different algorithms a more sophisticated and semiautomated pump } \\
\text { therapy once related to the time a sensor is worn or not worn [3] }\end{array}$ \\
\hline Hybrid closed-loop insulin delivery system & HCL & $\begin{array}{l}\text { These devices integrate CGM systems with an insulin pump including an } \\
\text { algorithm which automates insulin delivery [12] }\end{array}$ \\
\hline "Do-it-yourself" artificial pancreas systems (DIYAPS) & DIYAPS & $\begin{array}{l}\text { They involve the use of rt-CGM (or FGM with the addition of hardware } \\
\text { that allows conversion to rt-CGM), an algorithm that calculates insulin } \\
\text { doses, a communication device (like a smartphone), and an insulin pump. } \\
\text { Together, these systems automatically adjust basal rates and bolus doses } \\
\text { in response to CGM values. In simple terms, as blood glucose rises, the } \\
\text { system automatically delivers more insulin, and as it drops, the system } \\
\text { delivers less. There are currently three types of DIY closed-loop system: } \\
\text { Open APS, Looping, and Android APS. They differ in the combination of } \\
\text { pumps, user communication devices, hardware, and algorithms used [9, } \\
\text { 13] }\end{array}$ \\
\hline
\end{tabular}

health/diabetes related quality of life (HRQoL), and patient/ caregiver satisfaction. Our final selection was outlined in studies that were conducted with children, adolescents, and young adults exclusively with type 1 diabetes that reported any of the outcomes of interest: $\mathrm{HbA1c}, \mathrm{SH}, \mathrm{DKA}$, percentage in TIR, TBR, and TAR, HRQoL or patient/caregiver satisfaction. Comparisons between studies and meta-analysis were not a goal, nor performed. We excluded studies that did not meet the age criteria, that were not considered studies with an intervention in diabetes-related technology, nor review studies or expert opinion papers, nor pilot or past technology trials, nor those that they only focused on socioeconomic analysis.

Two reviewers (TJS, CK) worked independently to check eligibility of studies (title and abstract) and extracted the appropriate information in full-text articles for the remainder reviewers (TCR, MKP, RFA). Data extracted from the studies included year of publication, country, baseline characteristics of participants, type of intervention (type of insulin pump, CGMS or closed-loop system, and strategy applied for telemedicine), glycemic and patient-reported outcomes. We analyzed the following glycemic outcomes: (i) changes in $\mathrm{HbA} 1 \mathrm{c}(\% / \mathrm{mmol} / \mathrm{mol})$, (ii) changes in the number of $\mathrm{SH}$ episodes (below $54 \mathrm{mg} / \mathrm{dL}(3.0 \mathrm{mmol} / \mathrm{L}$ ) or an event associated with severe cognitive impairment (including coma and convulsions) requiring external assistance), (iii) changes in the number of people with DKA event, and (iv) changes in the mean $( \pm \mathrm{SD})$ percentage of TIR (percentage of readings in the glycemic range of $70-180 \mathrm{mg} / \mathrm{dl}(3.9-10.0 \mathrm{mmol} / \mathrm{L})$ per unit of time), TAR and TBR assessed with any continuous glucose monitoring systems [15-17]. We collected information on questionnaires that assessed the overall mean ( \pm SD) HRQoL score for each group at the end of the study.

\section{Results}

A total of 648 articles were identified and their titles and abstracts were screened for eligibility. After removing those articles that did not match the inclusion criteria, we assessed 191 studies; of them, 124 were excluded for various reasons (see Fig. 1). A total of 67 articles were included in our narrative synthesis; of these 19 are RCTs, 44 observational studies presenting real-world data, and 15 are cross-sectional surveys or interviews. We classified the included studies in four different areas in order to better assess their results, as follows: 14 on CSII, 9 on CGM systems, 22 on HCL systems (artificial pancreas), including 4 on DIYAPS (Supplemental Table 1), and 23 on telemedicine and telehealth (Supplemental Table 2). 
Fig. 1 Flow diagram across the review

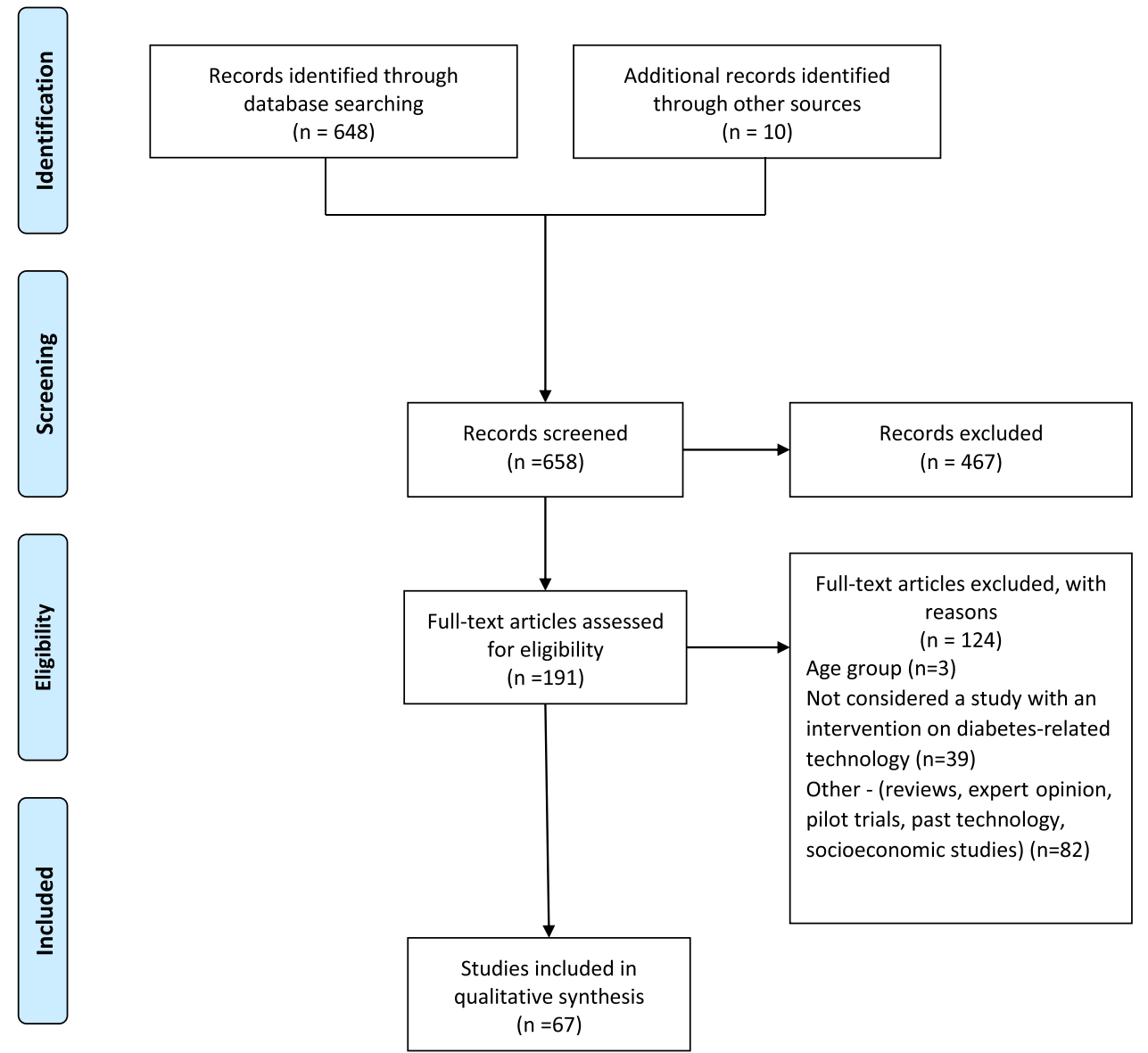

insertion site pain or local reaction, technical problems, and quality of life among different brand devices [30].

From a United Kingdom National Health System perspective, although CSII had little benefit, it was more expensive than MDI with a mean total cost ( $£ 1863,95 \%$ CI $£ 1620$ to $£ 2137$ ) with no additional quality-adjusted life-year (QALY) gains (-0.006 QALYs, 95\% CI - 0.031 to 0.018 QALYs) [31].

\section{Continuous Glucose Monitoring Systems}

Pediatric CGM use increased in national T1D registries and was associated with lower mean HbA1c, better glucose control, and fewer diabetes-related emergency visits, regardless of insulin delivery modality $[32,33]$. A large cohort of people with type 1 diabetes from 1 to 18 years compared patients on injections or pump, with or without sensor for CGM, and observed lower HbA1c and fewer DKA episodes in participants using either a pump or CGM or both. Pump without sensor experienced less SH episodes and pump with sensor experienced less DKA [33]. Interestingly, glycemic outcomes seem to be improved when information from CGM system was shared with caregivers [34]. 
A randomized trial comparing CGM and SMBG showed small statistically significant improvement in glycemic control over 26 weeks with CGM use in adolescents and young adults [35]. Another randomized trial showed that insulin pump therapy with CGM offering LGS significantly reduced fear of hypoglycemia not related to CGM adherence in children with type 1 diabetes and their parents [36].

In a cross-sectional study to evaluate the use of flash glucose monitoring, the glycemic variability defined by the $\mathrm{CV}$ modifies the relationship between the TIR and HbA1c/Glucose Management Indicator and should be considered when individualizing TIR targets, regardless of age or the type of treatment used [37].

\section{Hybrid Closed-Loop Insulin Delivery System and "Do-It-Yourself" Artificial Pancreas System}

Randomized controlled trials in pediatric age with HCL systems showed greater percentage of time that the glucose level was in a target range, less hyperglycemia and hypoglycemia, and better HbA1c levels than sensor-augmented pumps [6, 38-42]. Similarly, observational studies with real-world data presented more benefits with commercialized HCL systems with improved glycemic control, glycemic variability, and patient satisfaction in children and adolescents when time in auto mode was active [43-50]. In regards to the DIYAPS, no RCT was found, and the few articles were focused on assessing patients and caregivers' perspectives and satisfaction in using the DIYAPS [51-53]. It is noteworthy that one study assessed very young children with T1D, and it seemed to be safe as no episodes of severe hypoglycemia or DKA were reported [51]. However, users still identify the primary challenge of sourcing necessary devices and setting up the closed loop [52].

In addition, a few studies aimed to present data on logic algorithms assembling automated artificial intelligencebased decision support systems and they demonstrated to be safe during day and night $[54,55]$. Interviews and surveys focused on assessing patient's attitudes reported substantial benefits using the closed loop systems; however, they also identified ways in which the technology could be refined, and education and training tailored to optimize effective use and reduce management distress $[56,57]$.

\section{Telemedicine-Education}

Training using the Zoom Cloud Meetings platform (Zoom Video Communications, Inc, San Jose, CA, USA) seemed to be useful, especially in adult and motivated patients, whose satisfaction indices were high, and problems with platform very low [58]. Re mote training for candidates for $\mathrm{HCL}$ pump, MiniMed 670G using digital teleconference platforms provided continuous support for technological devices and improved the delivery of better care for T1D patients [59]. It is of note that probably some aspects of this training should be adapted for pediatric patients.

Results from a pilot study aimed to assess interventions in telehealth cognitive behavioral therapy have proven its usefulness in T1D pediatric patients younger than 7 years and their caregivers in reducing fear of hypoglycemia, emphasizing the potential cost-effective use for remote group sessions [60].

A web-based program prototype "Type 1 Teamwork," with six main topics such as "Being a Parent," "Parents as Partners," "Communicate," "Letting Go," "Getting Emotional," and "You Matter," was considered very relevant for both parents and care providers. This resource is potentially useful to be offered via web based or mobile apps [61].

\section{Telemedicine-Social Media}

Adolescents with T1D expressed interest in the use of social media as a tool to support diabetes management and increase engagement with their diabetes care team [62]. Specific implementation measures around privacy and professionalism should be considered when developing a social media intervention to facilitate communication between adolescents and care teams [62]. Social media like Facebook (Menlo Park, CA, USA) and Viber (Luxembourg, LU) were found to be an additional communication tool for adolescents and young people with type 1 diabetes and significantly lowered HbA1c compared to patients without social media use, as demonstrated in a retrospective and crosssectional study [63]. People using CSII were more likely to use both social media (Facebook and Viber) compared with those on MDI (Facebook only).

Web-based portal initiatives such as "Sugarsquare" should be tailored to fit parents' interests, and offer multiple options, as forums, chat, and links to access professional advice in a personal fashion, to be considered useful tools for pediatric diabetes care [64].

\section{Telemedicine-Routine Daily Care}

The accumulation of evidence on the effectiveness and safety of telehealth in diabetes care should contribute to implementing this approach in practical health care [65]. Remote medical care, or telehealth, had been practiced increasingly for people with T1D with positive impact on their metabolic control [66]. Telemedicine's usefulness, applied to diabetic retinopathy even before pandemics, has led to optimization of health care delivery in this field around the world [67]. Recently, the COVID19 pandemic made the telemedicine practice a necessary tool to ensure care worldwide [68-70]. Even during the most restricted lockdown, an Italian group of patients using rt-CGM and followed by telemedicine 
did not show worsening of their glycemic controls [71]. In another group tested during pandemics, results demonstrated that remote $\mathrm{HbAlc}$ monitoring via dried blood spot is feasible and offers an avenue to support assessment of glycemic control for patients seen via telemedicine [72]. Assessments from survey on people with type 1 diabetes during lockdown showed that at least two-thirds underwent changes in the management of their condition [73]. Data from the International Society for Pediatric and Adolescent Diabetes (ISPAD) also reported high degrees of migration to telemedicine/e-health tools [69].

Qualitative analyses have identified a number of unique benefits of telemedical interventions, including higher frequency of contacts, greater sense of patient's safety, ability to interact with patients in their own homes, more timely and accurate medical monitoring, and improved data management after a technical training for video consultations [74]. A good strategy to engage adolescents with T1D is to offer them a message platform to support behavior changes, interconnecting through apps with social interface, rewarding (grading and earning points), and "gamification" features are interesting tools for this age group [75].

Technology also allows the integration of care that goes beyond glycemic control, as demonstrated by the AID-GM (Advanced Intelligent Distant-Glucose Monitoring) webbased program for integration of blood glucose profile and other data (sleep patterns, physical activity, food intake, and other inputs), which may announce the dawn of what is called "e-Health" in diabetes care [76]. Remote monitoring in children with DM1 resulted in significant improvements in glycemic control (HbA1c, glycemic variability, and hypoglycemic frequency) [65]. However, inequalities in access to technology and eHealth even in high-income societies, with access to good and affordable health services, may happen [77].

\section{Discussion}

In this review of the literature of the past 5 years on current diabetes devices for those in the pediatric age range, we found an impressive transition from the use of insulin pumps and/or CGMs only to integrative devices with automated delivery systems. While a lot has changed in the past 5 years, including a pandemic period that precipitated a broader use of telemedicine in diabetes care [69], for many healthcare providers, caregivers and people with diabetes, such advances in diabetes technology, may represent an additional burden of care [78-80].

One of the most assertive advances in diabetes technology was the launching of pumps with predictive low glucose suspension (PLGS) system and turned diabetes management into a suitable and safe therapeutic option, especially for very young children with diabetes to prevent risk of severe hypoglycemia [18]. And it also seems to be effective in addressing age-specific challenges and able to improve glycemic control in children of all ages [81].

Since insulin discovery in 1921, different advances emerged to improve metabolic control, reduce diabetes chronic complications, and ameliorate QoL. Glucose monitoring was one of the most important tools that contributed to the improvement of glycemic control and its long-term consequences [82]. Drawing a timeline, we observe the spectacular transformations that have taken place over decades of diabetes management and the accelerated advances in recent years. Until the 1960s, glucose monitoring was performed through the measurement of glycosuria. In 1965, the first method of measuring capillary blood glucose, the Dextrostix, was performed, but was a semi-quantitative test, with high error rate [83]. The Dextrometer launched in 1980 was the first digital panel glucometer, followed by new generation devices, with lower costs and greater accuracy [83, 84]. Since the Diabetes Control and Complications Trial (DCCT) study [85], metabolic control was assessed by HbA1c, that reflects metabolic control of three to four months, showing a positive relationship with frequent assessment of self-monitoring of blood glucose (SMBG) [86, 87]. Nevertheless, HbA1c can be influenced by several clinical and personal conditions and does not reflect hypoglycemic events or glucose excursions.

The improvement of diabetes technologies and the need to assess and comprehend glycemic control, hypoglycemia, and glycemic variability led to the development of CGM systems, and nowadays intermittent CGMs (iCGM or FGM) and real-time CGM (rT-CGM) are available [82]. CGM systems provide a continuous measurement of interstitial glucose over time, allow to detect TIR, hypoglycemic and hyperglycemic events (time below or above range) and glucose variation (coefficient of variation-CV). Data of different observational studies and randomized control trials (RCT) reflects the spreading use of CGMs in the pediatric population and demonstrates that they can improve glycemic control by lowering mean $\mathrm{HbA1c}$, regardless of insulin delivery modality, reducing DKA episodes and increasing TIR with a reduction of time spent in hypo or hyperglycemia [29, 32-37, 88-90]. Notably, studies with the largest pediatric population are observational and only a few randomized studies demonstrated the impact of the CGM contribution in children and adolescents.

Given the greater glycemic outcomes with significantly fewer events of DKA, severe hypoglycemia, and with no hospital admission when using the HCL systems in automode [8, 38, 43, 45-47], and after an improved patient's uptake with these systems [56, 57, 91], it is foreseeable that diabetes care is becoming increasingly patient centered. Individualization of glucose control, aiming to minimize 
high glucose peaks while preventing hypoglycemia, and almost "automate" diabetes control is expected to be the next step to provide full CLS to all people living with T1D.

While a few commercial systems have been launched lately, the movement \#WeAreNotWaiting has disseminated technologies that are open source and available as do-ityourself (DIY) CLS or DIY artificial pancreas systems (APS). Currently, there are two different algorithms: Loop, that runs on iPhone, and OpenAPS, that runs on both iPhone and Android systems. In general, it is made up of an old pump device associated with a CGM system that synchronizes with an open-source platform that connects CGM in the cloud, the Nightscout project [92]. This platform allows real time access to a CGM data via personal website, smartwatch viewers, or apps and widgets available for smartphones. Although it means a lot for patients and caregivers, OpenAPS are still unlicensed products. A promising launching of a commercially available project, the Tidepool (Palo Alto, Ca, USA), using the Loop algorithm, is a hope to regulate it and enable patients to program and calculate their own algorithms to work with their CGM sensors and devices.

In an era of automation and very close to the artificial pancreas, Telemedicine and Telehealth also seem to be here to stay. Even before the pandemic, some initiatives in distance diabetes education and the use of social networks and interactive behavioral support groups were already being tested, with positive results [60, 92].

The pandemic certainly accelerated its broader implementation. Almost all participants agreed with the concept of telemedicine, favoring telephone and video calls as their preferred means of communication also for future care [73, 93], the strategy has proved to be valid not only for patients, but also for caregivers and health professionals [62]. The use of platforms such as Zoom, Viber and Facebook, widely used for group and workgroup connections has proved to be an especially useful tool for teenagers and caregivers, both from an educational point of view and for optimizing the use of pumps and other devices, with positive results in the guidance and glycemic control of patients [58, 63, 64]. And in the context of the epidemiological emergency of the COVID19 pandemic, several groups used the strategy to ensure training and follow-up of their patients $[58,59]$. And there is certainly a place for these strategies regardless of the current epidemiological context. Minimizing distances and optimizing time add value to digital tools.

For the daily care routine of patients such as T1D, telehealth initiatives were pushed forward especially after 2020 [66, 69, 73]. Telephone and video calls, electronic messages and use of telemedicine platforms were used by several groups worldwide $[68,70,94]$; however, there is a need for training in the use of digital tools [74], and an effort to reduce discrepancy in access, even in economically developed countries [77], which includes internet speed and safety. The most important question is the impact of distance care on patients' glycemic control and, although data are still limited, there is favorable evidence for improved glycemic control, reduction of severe hypoglycemia and in the incidence of DKA [65, 71]. Digital platforms and initiatives capable of increasing patients' access to induce transformation on general health care strategies, such as "Sugarsquare," "gamification apps," and "Advanced Intelligent Distant Glucose Monitoring," appear to be promising e-health initiatives that find good acceptance in the chronic care required by T1D, especially for this new generation of pediatric and adolescents [64, 75-77, 94]. All of this must not ignore the need to design equitable eHealth solutions to address social/ economic gaps in society [77]. Promising results have been demonstrated with multidisciplinary team care [94] and telemedicine as a useful tool to deliver diabetes care for the transitional age group, from pediatric age to adulthood [95].

\section{Conclusion}

Healthcare in this century has been converging with the technological advances of the last decades. Considering T1D management, the last decade brought new types of insulin and technological devices, allowing an even more intensive glycemic control, largely due to the broader us of CGM. The goals of glycemic control include stabilization of glycemic variability to achieve glycemic targets, in addition to the traditional measurement of $\mathrm{HbA1c}$. In the past 5 years, insulin pumps have been approaching the long-awaited artificial pancreas, but so far, the big breakthrough is still the suspension of insulin infusion in hypoglycemia (or risk of), ensuring protection from severe episodes of hypoglycemia, reducing worries, and increasing confidence and tranquility of caregivers with these systems. The future is to be reached, as we can count on almost full closed loop systems, regrettably not to all people living with T1D.

Children, adolescents, and young adults with chronic diseases need intensive education on selfcare. Particularly for T1D, it is beneficial when it comes along with tele-education and telemonitoring. Telemedicine and telehealth, with simple tools already available, like telephone/video calls and text messages, show promising data, but specific platforms for T1D can be even more assertive. It is important that healthcare systems worldwide include these strategies more equitably for children and adolescents. Possibly, some patients may benefit even more from tele-education and telehealth in diabetes, with a focus on higher-risk groups (persistently high $\mathrm{HbA} 1 \mathrm{c}$ and/or low socioeconomic status) to ensure that existing disparities in health outcomes and access to advanced technology do not increase. 
Supplementary Information The online version contains supplementary material available at https://doi.org/10.1007/s40124-021-00248-7.

Author Contribution TS was responsible for the conception and design of the study. TS and CK selected the articles. All authors extracted the data and conducted the narrative synthesis. All authors drafted the whole manuscript. All authors revised this work for important intellectual content and approved the final manuscript.

Availability of Data and Material Not applicable.

Code Availability Not applicable.

\section{Declarations}

Ethics Approval and Consent to Participate Not applicable.

Consent for Publication Not applicable.

Conflict of Interest The authors declare no competing interests.

\section{References}

Papers of particular interest, published recently, have been highlighted as:

- Of importance

$\bullet$ Of major importance

1. Sundberg F, Barnard K, Cato A, de Beaufort C, DiMeglio LA, Dooley G, et al. Managing diabetes in preschool children. Pediatr Diabetes. 2017;18:499-517. https://doi.org/10.1111/pedi. 12554.

2.- Sherr JL, Tauschman M, Battelino T, de Bock M, Forlenza G, Roman R, et al. ISPAD Clinical Practice Consensus Guidelines 2018 Diabetes Technologies. Pediatr Diabetes. 2018;19:302-25. https://doi.org/10.1111/pedi.12731.. (Reviews evidence on diabetes technology in children, adolescents, and young adults and to provide practical advice and approaches on their use. This reference provides the most updated consensus on diabetes technologies for pediatric type 1 diabetes performed by an international society for pediatric diabetes and include topics on insulin pumps, CGM, sensor augmented pumps, closed loop systems, diabetes apps and automated decision support systems, downloading technologies, telehealth, quality of life issues related to diabetes technology, and a consideration of how to use these technologies in resource-limited situations.)

3. Kapellen TM. Pharmacotherapy of children and adolescents with type 1 diabetes mellitus. Handb Exp Pharmacol. 2020;261:10518. https://doi.org/10.1007/164_2019_245.

4. Bergenstal RM, Tamborlane WV, Ahmann A, Buse JB, Dailey G, Davis SN, et al. Effectiveness of sensor-augmented insulinpump therapy in type 1 diabetes. N Engl J Med. 2010;363:31120. https://doi.org/10.1056/nejmoa1002853.

5. Smalley E. Medtronic automated insulin delivery device gets FDA nod. Nat Biotechnol. 2016;34:1220. https://doi.org/10. 1038/nbt1216-1220.

6. Tauschmann M, Thabit H, Bally L, Allen JM, Hartnell S, Wilinska ME, et al. Closed-loop insulin delivery in suboptimally controlled type 1 diabetes: a multicentre, 12 -week randomised trial. Lancet. 2018;392:1321-9. https://doi.org/ 10.1016/S0140-6736(18)31947-0.

7. FDA approves first automated insulin delivery device for type 1 diabetes I FDA n.d. https://www.fda.gov/news-events/pressannouncements/fda-approves-first-automated-insulin-deliverydevice-type-1-diabetes (accessed May 13, 2021).

8. Beato-Víbora PI, Gamero-Gallego F, Ambrojo-López A, GilPoch E, Martin-Romo I, Arroyo-Díez FJ. Rapid improvement in time in range after the implementation of an advanced hybrid closed-loop system in adolescents and adults with type 1 diabetes. Diabetes Technol Ther. 2021. https://doi.org/10. 1089/dia.2021.0037.

9. Crabtree TSJ, McLay A, Wilmot EG. DIY artificial pancreas systems: here to stay? Pract Diabetes. 2019;36:63-8. https:// doi.org/10.1002/pdi.2216.

10. Tauschmann M, Hovorka R. Technology in the management of type 1 diabetes mellitus-current status and future prospects. Nat Rev Endocrinol. 2018;14:464-75. https://doi.org/10.1038/ s41574-018-0044-y.

11. Eisenstein E, Kopacek C, Cavalcante SS, Neves AC, Fraga GP, Messina LA. Telemedicine: a bridge over knowledge gaps in healthcare. Curr Pediatr Rep. 2020;8:93-8. https://doi.org/10. 1007/s40124-020-00221-w.

12. Leelarathna L, Choudhary P, Wilmot EG, Lumb A, Street T, Kar P, et al. Hybrid closed-loop therapy: where are we in 2021? Diabetes, Obes Metab. 2021;23:655-60. https://doi.org/ 10.1111/dom.14273.

13. Dowling L, Wilmot EG, Choudhary P. Do-it-yourself closedloop systems for people living with type 1 diabetes. Diabet Med. 2020;37:1977-80. https://doi.org/10.1111/dme.14321.

14 Moher D, Liberati A, Tetzlaff J, Altman DG, Altman D, Antes G, et al. Preferred reporting items for systematic reviews and meta-analyses: the PRISMA statement. PLoS Med. 2009;6:e1000097. https://doi.org/10.1371/journal.pmed.10000 97.

15. Abraham MB, Jones TW, Naranjo D, Karges B, Oduwole A, Tauschmann M, et al. ISPAD Clinical Practice Consensus Guidelines 2018: assessment and management of hypoglycemia in children and adolescents with diabetes. Pediatr Diabetes. 2018;19:178-92. https://doi.org/10.1111/pedi.12698.

16. Agiostratidou G, Anhalt H, Ball D, Blonde L, Gourgari E, Harriman $\mathrm{KN}$, et al. Standardizing clinically meaningful outcome measures beyond $\mathrm{HbA} 1 \mathrm{c}$ for type 1 diabetes: a consensus report of the American Association of Clinical Endocrinologists, the American Association of Diabetes Educators, the American Diabetes Association, the Endocrine Society, JDRF International, The Leona M and Harry B Helmsley Charitable Trust, the Pediatric Endocrine Society, and the T1D Exchange. Diabetes Care. 2017;40:1622-30. https://doi.org/10.2337/dc17-1624.. (Provides current methodology for diabetes research support performed by a Steering Committee of main international diabetes societies that developed definitions for hypoglycemia, hyperglycemia, time in range, and DKA in type 1 diabetes. The definitions reflect their assessment of the outcome's short- and long-term clinical impact on people with type 1 diabetes.•)

17. Rewers MJ, Pillay K, de Beaufort C, Craig ME, Hanas R, Acerini CL, et al. Assessment and monitoring of glycemic control in children and adolescents with diabetes. Pediatr Diabetes. 2014;15:102-14. https://doi.org/10.1111/pedi.12190.

18. Gaweł WB, Deja G, Kamińska H, Tabor A, Skała-Zamorowska E, Jarosz-Chobot P. How does a predictive low glucose suspend (PLGS) system tackle pediatric lifespan challenges in diabetes treatment? Real world data analysis Pediatr Diabetes. 2020;21:280-7. https://doi.org/10.1111/pedi.12944. 
19. Burckhardt M-A, Smith GJ, Cooper MN, Jones TW, Davis EA. Real-world outcomes of insulin pump compared to injection therapy in a population-based sample of children with type 1 diabetes. Pediatr Diabetes. 2018;19:1459-66. https://doi.org/ 10.1111/pedi.12754.

20. Karges B, Schwandt A, Heidtmann B, Kordonouri O, Binder E, Schierloh U, et al. Association of insulin pump therapy vs insulin injection therapy with severe hypoglycemia, ketoacidosis, and glycemic control among children, adolescents, and young adults with type 1 diabetes. JAMA. 2017;318:1358. https://doi.org/10.1001/jama.2017.13994.

21. Lang EG, King BR, Miller MN, Dunn SV, Price DA, Foskett DC. Initiation of insulin pump therapy in children at diagnosis of type 1 diabetes resulted in improved long-term glycemic control. Pediatr Diabetes. 2017;18:26-32. https://doi.org/10. 1111/pedi.12357.

22. Szypowska A, Schwandt A, Svensson J, Shalitin S, CardonaHernandez R, Forsander G, et al. Insulin pump therapy in children with type 1 diabetes: analysis of data from the SWEET registry. Pediatr Diabetes. 2016;17:38-45. https://doi.org/10. 1111/pedi.12416.

23. Sherr JL, Hermann JM, Campbell F, Foster NC, Hofer SE, Allgrove $\mathrm{J}$, et al. Use of insulin pump therapy in children and adolescents with type 1 diabetes and its impact on metabolic control: comparison of results from three large, transatlantic paediatric registries. Diabetologia. 2016;59:87-91. https://doi. org/10.1007/s00125-015-3790-6.

24. Mueller-Godeffroy E, Vonthein R, Ludwig-Seibold C, Heidtmann B, Boettcher C, Kramer M, et al. Psychosocial benefits of insulin pump therapy in children with diabetes type 1 and their families: the pumpkin multicenter randomized controlled trial. Pediatr Diabetes. 2018;19:1471-80. https://doi.org/10. 1111/pedi.12777.

25. Hussain T, Akle M, Nagelkerke N, Deeb A. Comparative study on treatment satisfaction and health perception in children and adolescents with type 1 diabetes mellitus on multiple daily injection of insulin, insulin pump and sensor-augmented pump therapy. SAGE Open Med. 2017;5:205031211769493. https:// doi.org/10.1177/2050312117694938.

26. Abraham MB, Nicholas JA, Smith GJ, Fairchild JM, King BR, Ambler GR, et al. Reduction in hypoglycemia with the predictive low-glucose management system: a long-term randomized controlled trial in adolescents with type 1 diabetes. Diabetes Care. 2018;41:303-10. https://doi.org/10.2337/dc17-1604.

27. Battelino T, Nimri R, Dovc K, Phillip M, Bratina N. Prevention of hypoglycemia with predictive low glucose insulin suspension in children with type 1 diabetes: a randomized controlled trial. Diabetes Care. 2017;40:764-70. https://doi.org/ $10.2337 / \mathrm{dc} 16-2584$.

28. Wadwa RP, Chase HP, Raghinaru D, Buckingham BA, Hramiak I, Maahs DM, et al. Ketone production in children with type 1 diabetes, ages $4-14$ years, with and without nocturnal insulin pump suspension. Pediatr Diabetes. 2017;18:422-7. https://doi.org/10.1111/pedi.12410.

29. Lawson ML, Verbeeten KC, Courtney JM, Bradley BJ, McAssey K, Clarson C, et al. Timing of CGM initiation in pediatric diabetes: the CGM TIME trial. Pediatr Diabetes. 2021;22:279-87. https://doi.org/10.1111/pedi.13144.. (Is a RCT that determined whether timing of CGM initiation offering low glucose suspend. They presented data that simultaneous initiation of CGM with the option of lowglucose suspension and insulin pump therapy was associated with greater CGM adherence in the first 6 months compared to initiation of CGM with option of low-glucose suspension 6 months after starting pump therapy.)
30. Rachmiel M, Levy-Shraga Y, Gruber N, Pinhas-Hamiel O, Barash G, Pivko-Levy D, et al. Comparing insulin pump devices in real life: the awesome study group prospective experience. Diabetes Technol Ther. 2019;21:138-45. https://doi.org/10.1089/ dia.2018.0309.

31. Blair J, McKay A, Ridyard C, Thornborough K, Bedson E, Peak M, et al. Continuous subcutaneous insulin infusion versus multiple daily injections in children and young people at diagnosis of type 1 diabetes: the SCIPI RCT. Health Technol Assess. 2018;22:1-112. https://doi.org/10.3310/hta22420.. (Provides comparisons on the efficacy, safety, and cost utility of continuous subcutaneous insulin infusion (CSII) with multiple daily injection (MDI) regimens during the first year following diagnosis of type 1 diabetes in children and young people cost-effectiveness on using diabetes technologies. They concluded that no clinical benefit of CSII over MDI was identified in children and young people in the UK setting, and treatment with either regimen was suboptimal in achieving HbA1c thresholds. CSII was not cost-effective.)

32. DeSalvo DJ, Miller KM, Hermann JM, Maahs DM, Hofer SE, Clements MA, et al. Continuous glucose monitoring and glycemic control among youth with type 1 diabetes: international comparison from the T1D Exchange and DPV Initiative. Pediatr Diabetes. 2018;19:1271-5. https://doi.org/10.1111/pedi.12711.

33 Cardona-Hernandez R, Schwandt A, Alkandari H, Bratke H, Chobot A, Coles N, et al. Glycemic outcome associated with insulin pump and glucose sensor use in children and adolescents with type 1 diabetes. data from the International Pediatric Registry SWEET. Diabetes Care. 2021;44:1176-84. https://doi.org/ 10.2337/dc20-1674.

34. Welsh JB, Derdzinski M, Parker AS, Puhr S, Jimenez A, Walker T. Real-time sharing and following of continuous glucose monitoring data in youth. Diabetes Ther. 2019;10:751-5. https://doi. org/10.1007/s13300-019-0571-0.

35.• Laffel LM, Kanapka LG, Beck RW, Bergamo K, Clements MA, Criego A, et al. Effect of continuous glucose monitoring on glycemic control in adolescents and young adults with type 1 diabetes: a randomized clinical trial. JAMA - J Am Med Assoc. 2020;323:2388-96. https://doi.org/10.1001/jama.2020.6940.. (Is a RCT that found that the use of the continuous glucose monitoring when compared with standard blood glucose monitoring among adolescents and young adults with type 1 diabetes resulted in statistically significant improvement in glycemic control over 6 months. This was the first study to demonstrate the benefits of the use of CGM against SBGM in children and adolescents.)

36. Verbeeten KC, Perez Trejo ME, Tang K, Chan J, Courtney JM, Bradley BJ, et al. Fear of hypoglycemia in children with type 1 diabetes and their parents: effect of pump therapy and continuous glucose monitoring with option of low glucose suspend in the CGM TIME trial. Pediatr Diabetes. 2021;22:288-93. https:// doi.org/10.1111/pedi.13150.

37. Díaz-Soto G, Bahíllo-Curieses MP, Jimenez R, de la Nieto MO, Gomez E, Torres B, et al. The relationship between glycosylated hemoglobin time-in-range and glycemic variability in type 1 diabetes patients under flash glucose monitoring. Endocrinol Diabetes Nutr. 2021;68:465-71. https://doi.org/10.1016/j.endinu.2020. 09.008 .

38.• Breton MD, Kanapka LG, Beck RW, Ekhlaspour L, Forlenza GP, Cengiz E, et al. A randomized trial of closed-loop control in children with type 1 diabetes. N Engl J Med. 2020;383:836-45. https://doi.org/10.1056/nejmoa2004736.. (Is a RCT that compared the use of a closed-loop system with a sensor-augmented insulin pump on the glucose level of children with type 1 diabetes. They found that the glucose range was in the 
target range when closed-loop system was used for a greater percentage of time.)

39. Brown SA, Kovatchev BP, Raghinaru D, Lum JW, Buckingham BA, Kudva YC, et al. Six-month randomized, multicenter trial of closed-loop control in type 1 diabetes. N Engl J Med. 2019;381:1707-17. https://doi.org/10.1056/NEJMoa1907863.

40. Ekhlaspour L, Forlenza GP, Chernavvsky D, Maahs DM, Wadwa $\mathrm{RP}$, Deboer MD, et al. Closed loop control in adolescents and children during winter sports: use of the Tandem Control-IQ AP system. Pediatr Diabetes. 2019;20:759-68. https://doi.org/ 10.1111/pedi.12867.

41. Renard E, Tubiana-Rufi N, Bonnemaison-Gilbert E, Coutant R, Dalla-Vale F, Farret A, et al. Closed-loop driven by controlto-range algorithm outperforms threshold-low-glucose-suspend insulin delivery on glucose control albeit not on nocturnal hypoglycaemia in prepubertal patients with type 1 diabetes in a supervised hotel setting. Diabetes Obes Metab. 2019;21:183-7. https://doi.org/10.1111/dom.13482.

42. Biester T, Nir J, Remus K, Farfel A, Muller I, Biester S, et al. DREAM5: An open-label, randomized, cross-over study to evaluate the safety and efficacy of day and night closed-loop control by comparing the MD-Logic automated insulin delivery system to sensor augmented pump therapy in patients with type 1 diabetes at home. Diabetes, Obes Metab. 2019;21:822-8. https:// doi.org/10.1111/dom.13585.

43. Lum J, Bailey R, Barnes-Lomen V, Naranjo D, Hood K, Lal RA, et al. A Real-world prospective study of the safety and effectiveness of the loop open source automated insulin delivery system. Diabetes Technol Ther. 2020. https://doi.org/10.1089/dia. 2020.0535. .. (Is a prospective real-world observational study that evaluated the safety and effectiveness of the Loop DoIt-Yourself automated insulin delivery system. They found that the Loop open source system can be initiated with community-developed resources and used safely and effectively by adults and children with type 1 diabetes.)

44. Messer LH, Campbell K, Pyle L, Forlenza GP. Basal-IQ technology in the real world: satisfaction and reduction of diabetes burden in individuals with type 1 diabetes. Diabet Med. 2020;36:e14381. https://doi.org/10.1111/dme.14381.

45. Petrovski G, Al Khalaf F, Campbell J, Umer F, Almajaly D, Hamdan M, et al. One-year experience of hybrid closed-loop system in children and adolescents with type 1 diabetes previously treated with multiple daily injections: drivers to successful outcomes. Acta Diabetol. 2021;58:207-13. https://doi.org/10. 1007/s00592-020-01607-4.

46. Schoelwer MJ, Kanapka LG, Wadwa RP, Breton MD, Ruedy KJ, Ekhlaspour L, et al. Predictors of Time-in-Range (70-180 $\mathrm{mg} / \mathrm{dL}$ ) Achieved using a closed-loop control system. Diabetes Technol Ther. 2021;475:481. https://doi.org/10.1089/dia.2020. 0646.

47. Beato-Víbora PI, Gallego-Gamero F, Lázaro-Martín L, del Romero-Pérez M, Arroyo-Díez FJ. Prospective analysis of the impact of commercialized hybrid closed-loop system on glycemic control, glycemic variability, and patient-related outcomes in children and adults: a focus on superiority over predictive low-glucose suspend technology. Diabetes Technol Ther. 2020;22:912-9. https://doi.org/10.1089/dia.2019.0400.

48. Duffus SH, Taani ZA, Slaughter JC, Niswender KD, Gregory JM. Increased proportion of time in hybrid closed-loop "Auto Mode" is associated with improved glycaemic control for adolescent and young patients with adult type 1 diabetes using the MiniMed 670G insulin pump. Diabetes, Obes Metab. 2020;22:68893. https://doi.org/10.1111/dom.13912.

49. Lal RA, Basina M, Maahs DM, Hood K, Buckingham B, Wilson DM. One year clinical experience of the first commercial hybrid closed-loop system. Diabetes Care. 2019;42:2190-6. https://doi.org/10.2337/dc19-0855.

50. Stone MP, Agrawal P, Chen X, Liu M, Shin J, Cordero TL, et al. Retrospective analysis of 3-month real-world glucose data after the MiniMed 670G system commercial launch. Diabetes Technol Ther. 2018;20:689-92. https://doi.org/10.1089/ dia.2018.0202.

51. Petruzelkova L, Jiranova P, Soupal J, Kozak M, Plachy L, Neuman V, et al. Pre-school and school-aged children benefit from the switch from a sensor-augmented pump to an AndroidAPS hybrid closed loop: a retrospective analysis. Pediatr Diabetes. 2021;24:594-604. https://doi.org/10.1111/pedi.13190.

52 Braune K, O’Donnell S, Cleal B, Lewis D, Tappe A, Willaing I, et al. Real-world use of do-it-yourself artificial pancreas systems in children and adolescents with type 1 diabetes: online survey and analysis of self-reported clinical outcomes. JMIR MHealth UHealth. 2019;7:e14087. https://doi.org/10.2196/14087.

53. Lee JM, Newman MW, Gebremariam A, Choi P, Lewis D, Nordgren W, et al. Real-world use and self-reported health outcomes of a patient-designed do-it-yourself mobile technology system for diabetes: lessons for mobile health. Diabetes Technol Ther. 2017;19:209-19. https://doi.org/10.1089/dia.2016.0312.

54. Nimri R, Bratina N, Kordonouri O, Avbelj Stefanija M, Fath M, Biester T, et al. MD-Logic overnight type 1 diabetes control in home settings: a multicentre, multinational, single blind randomized trial. Diabetes, Obes Metab. 2017;19:553-61. https:// doi.org/10.1111/dom.12852.

55. Buckingham BA, Forlenza GP, Pinsker JE, Christiansen MP, Wadwa RP, Schneider J, et al. Safety and feasibility of the OmniPod Hybrid Closed-Loop System in adult, adolescent, and pediatric patients with type 1 diabetes using a personalized model predictive control algorithm. Diabetes Technol Ther. 2018;20:257-62. https://doi.org/10.1089/dia.2017.0346.

56. Lawton J, Blackburn M, Rankin D, Allen JM, Campbell FM, Leelarathna L, et al. Participants' experiences of, and views about, daytime use of a day-and-night hybrid closed-loop system in real life settings: longitudinal qualitative study. Diabetes Technol Ther. 2019;21:119-27. https://doi.org/10.1089/dia. 2018.0306

57. Adams RN, Tanenbaum ML, Hanes SJ, Ambrosino JM, Ly TT, Maahs DM, et al. Psychosocial and human factors during a trial of a hybrid closed loop system for type 1 diabetes management. Diabetes Technol Ther. 2018;20:648-53. https://doi.org/10. 1089/dia.2018.0174.

58. Vigersky RA, Velado K, Zhong A, Agrawal P, Cordero TL. The effectiveness of virtual training on the MiniMed ${ }^{\mathrm{TM}} 670 \mathrm{G}$ System in people with type 1 diabetes during the COVID-19 pandemic. Diabetes Technol Ther. 2021;23:104-9. https://doi.org/10.1089/ dia.2020.0234.

59. Gómez AM, Henao D, Parra D, Kerguelen A, Pinilla MV, Muñoz $\mathrm{OM}$, et al. Virtual training on the hybrid close loop system in people with type 1 diabetes (T1D) during the COVID-19 pandemic. Diabetes Metab Syndr Clin Res Rev. 2021;15:243-7. https://doi.org/10.1016/j.dsx.2020.12.041.

60. Patton SR, Clements MA, Marker AM, Nelson EL. Intervention to reduce hypoglycemia fear in parents of young kids using video-based telehealth (REDCHiP). Pediatr Diabetes. 2020;21:112-9. https://doi.org/10.1111/pedi.12934.

61. Whittemore R, Zincavage RM, Jaser SS, Grey M, Coleman JL, Collett D, et al. Development of an eHealth program for parents of adolescents with type 1 diabetes. Diabetes Educ. 2018;44:7282. https://doi.org/10.1177/0145721717748606.

62. Malik FS, Panlasigui N, Gritton J, Gill H, Yi-Frazier JP, Moreno MA. Adolescent perspectives on the use of social media to support type 1 diabetes management. J Med Internet Res. 2019;21:12149. https://doi.org/10.2196/12149. 
63. Petrovski G, Zivkovic M. Are we ready to treat our diabetes patients using social media? Yes, we are. J Diabetes Sci Technol. 2019;13:171-5. https://doi.org/10.1177/1932296818 795441.

64. Boogerd E, Maas-Van Schaaijk NM, Sas TC, Clement-De Boers A, Smallenbroek M, Nuboer R, et al. Sugarsquare, a Web-based patient portal for parents of a child with type 1 diabetes: multicenter randomized controlled feasibility trial. J Med Internet Res. 2017;19:6639. https://doi.org/10.2196/jmir.6639.

65. Laptev DN, Emelyanov AO, Samoilova YG, Khramova EB, Petriaikina EE, Rybkina IG, et al. Remote monitoring and treatment of children and adolescents with type 1 diabetes. Probl Endokrinol (Mosk). 2020;66:50-60. https://doi.org/10.14341/ probl12201.

66. Döğer E, Bozbulut R, ŞebnemSoysal AA, Ercan Ş, Uğurlu AK, Akbaş ED, et al. Effect of telehealth system on glycemic control in children and adolescents with type 1 diabetes. JCRPE J Clin Res Pediatr Endocrinol. 2019;11:70-5. https://doi.org/10.4274/ jcrpe.galenos.2018.2018.0017.

67. Flores R, Donoso R, Anguita R. Management of diabetic retinopathy using telemedicine and network integration. Rev Med Chil. 2019;147:444-50. https://doi.org/10.4067/S0034-98872 019000400444.

68 Odeh R, Gharaibeh L, Daher A, Kussad S, Alassaf A. Caring for a child with type 1 diabetes during COVID-19 lockdown in a developing country: challenges and parents' perspectives on the use of telemedicine. Diabetes Res Clin Pract. 2020;168:108393. https://doi.org/10.1016/j.diabres.2020.108393.

69. Elbarbary NS, Santos TJ, Beaufort C, Agwu JC, Calliari LE, Scaramuzza AE. COVID -19 outbreak and pediatric diabetes: perceptions of health care professionals worldwide. Pediatr Diabetes. 2020;21:1083-92. https://doi.org/10.1111/pedi.13084.

70. Krisiunas E, Sibomana L. Benefits of technology in the age of COVID-19 and diabetes mobile phones from a Rwanda perspective. J Diabetes Sci Technol. 2020;14:748-9. https://doi.org/10. $1177 / 1932296820930032$

71. Predieri B, Leo F, Candia F, Lucaccioni L, Madeo SF, Pugliese $\mathrm{M}$, et al. Glycemic control improvement in Italian children and adolescents with type 1 diabetes followed through telemedicine during lockdown due to the COVID-19 pandemic. Front Endocrinol (Lausanne). 2020;11:1. https://doi.org/10.3389/fendo. 2020.595735.

72. Roberts AJ, Malik F, Pihoker C, Dickerson JA. Adapting to telemedicine in the COVID-19 era: feasibility of dried blood spot testing for hemoglobin A1c. Diabetes Metab Syndr Clin Res Rev. 2021;15:433-7. https://doi.org/10.1016/j.dsx.2021.02.010.

73. Tejera-Perez C, Moreno-Pérez Ó, Rios J, Reyes-García R. People living with type 1 diabetes point of view in COVID-19 times (COVIDT1 study): disease impact, health system pitfalls and lessons for the future. Diabetes Res Clin Pract. 2021;171:108547. https://doi.org/10.1016/j.diabres.2020.108547.

74. Frielitz F-S, Dördelmann J, Lemke S, Lange K, Hiort O, Katalinic A, et al. Assessing the benefits and challenges of video consultations for the treatment of children with type 1 diabetes-a qualitative study among diabetes professionals. Exp Clin Endocrinol Diabetes. 2020. https://doi.org/10.1055/a-1149-8814.

75. Kaushal T, Montgomery KA, Simon R, Lord K, Dougherty J, Katz LEL, et al. MyDiaText ${ }^{\mathrm{TM}}$ : feasibililty and functionality of a text messaging system for youth with type 1 diabetes. Diabetes Educ. 2019;45:253-9. https://doi.org/10.1177/0145721719 837895 .

76. Salvi E, Bosoni P, Tibollo V, Kruijver L, Calcaterra V, Sacchi $\mathrm{L}$, et al. Patient-generated health data integration and advanced analytics for diabetes management: the AID-GM platform. Sensors (Switzerland). 2020;20:128. https://doi.org/10.3390/s2001 0128 .
77. Hansen AH, Bradway M, Broz J, Claudi T, Henriksen Ø, Wangberg $\mathrm{SC}$, et al. Inequalities in the use of eHealth between socioeconomic groups among patients with type 1 and type 2 diabetes: cross-sectional study. J Med Internet Res. 2019;21:e13615. https://doi.org/10.2196/13615.

78. Commissariat PV, Harrington KR, Whitehouse AL, Miller KM, Hilliard ME, Van Name M, et al. "I'm essentially his pancreas": parent perceptions of diabetes burden and opportunities to reduce burden in the care of children $<8$ years old with type 1 diabetes. Pediatr Diabetes. 2020;21:377-83. https://doi.org/10. 1111/pedi.12956.

79 Acerini C. The rise of technology in diabetes care. Not all that is new is necessarily better. Pediatr Diabetes. 2016;17:168-73. https://doi.org/10.1111/pedi.12366.

80. Messer LH, Cook PF, Tanenbaum ML, Hanes S, Driscoll KA, Hood KK. CGM benefits and burdens: two brief measures of continuous glucose monitoring. J Diabetes Sci Technol. 2019;13:1135-41. https://doi.org/10.1177/1932296819832909.

81. Biester T, Kordonouri O, Holder M, Remus K, Kieninger-Baum $\mathrm{D}$, Wadien T, et al. "Let the algorithm do the work": reduction of hypoglycemia using sensor-augmented pump therapy with predictive insulin suspension (SmartGuard) in pediatric type 1 diabetes patients. Diabetes Technol Ther. 2017;19:173-82. https://doi.org/10.1089/dia.2016.0349.

82.• Danne T, Nimri R, Battelino T, Bergenstal RM, Close KL, DeVries JH, et al. International consensus on use of continuous glucose monitoring. Diabetes Care. 2017;40:1631-40. https:// doi.org/10.2337/dc17-1600.. (Provides most updated consensus on the use of CGM in clinical practice. They presented data on the advanced metrics of assessing continuous glucose data appropriate as outcome parameters that complement HbA1c for a wide range of patients with diabetes and that it should be considered for use to help them improve glycemic control when appropriate educational and technical support is available.)

83. Alberti KGMM, Middleton GG, Caird FI. The accuracy of dextrostix in the estimation of blood-sugar. Lancet. 1965;286:31921. https://doi.org/10.1016/S0140-6736(65)90289-8.

84. Hirsch I. Introduction: History of glucose monitoring. Role Contin. Glucose Monit. Diabetes Treat., American Diabetes Association; 2018, p. 1-1. https://doi.org/10.2337/db20181-1

85. Nathan DM, Genuth S, Lachin J, Cleary P, Crofford O, Davis M, et al. The effect of intensive treatment of diabetes on the development and progression of long-term complications in insulindependent diabetes mellitus. N Engl J Med. 1993;329:977-86. https://doi.org/10.1056/NEJM199309303291401.

86. Cryer PE. Hypoglycemia in type 1 diabetes mellitus. Endocrinol Metab Clin North Am. 2010;39:641-54. https://doi.org/ 10.1016/j.ecl.2010.05.003.

87. Ziegler R, Heidtmann B, Hilgard D, Hofer S, Rosenbauer J, Holl R. Frequency of SMBG correlates with HbA1c and acute complications in children and adolescents with type 1 diabetes. Pediatr Diabetes. 2011;12:11-7. https://doi.org/10.1111/j.13995448.2010.00650.x.

88. Mulinacci G, Alonso GT, Snell-Bergeon JK, Shah VN. Glycemic outcomes with early initiation of continuous glucose monitoring system in recently diagnosed patients with type 1 diabetes. Diabetes Technol Ther. 2019;21:6-10. https://doi.org/10.1089/ dia.2018.0257.

89. Picard S, Bonnemaison-Gilbert E, Leutenegger E, Barat P. Optimization of insulin regimen and glucose outcomes with shortterm real-time continuous glucose monitoring (RT-CGM) in type 1 diabetic children with sub-optimal glucose control on multiple daily injections: the pediatric DIACCOR study. Arch Pediatr. 2019;26:95-101. https://doi.org/10.1016/j.arcped.2018. 11.010 . 
90. Massa GG, Gys I, Bevilacqua E, Wijnands A, Zeevaert R. Comparison of flash glucose monitoring with real time continuous glucose monitoring in children and adolescents with type 1 diabetes treated with continuous subcutaneous insulin infusion. Diabetes Res Clin Pract. 2019;152:111-8. https://doi.org/10. 1016/j.diabres.2019.05.015.

91. Messer LH, Forlenza GP, Sherr JL, Wadwa RP, Buckingham BA, Weinzimer SA, et al. Optimizing hybrid closed-loop therapy in adolescents and emerging adults using the MiniMed 670G System. Diabetes Care. 2018;41:789-96. https://doi.org/10.2337/ dc17-1682.

92. Lewis D. History and perspective on DIY closed looping. J Diabetes Sci Technol. 2019;13:790-3. https://doi.org/10.1177/ 1932296818808307.

93. Fung A, Irvine M, Ayub A, Ziabakhsh S, Amed S, Hursh BE. Evaluation of telephone and virtual visits for routine pediatric diabetes care during the COVID-19 pandemic. J Clin Transl Endocrinol. 2020;22: 100238. https://doi.org/10.1016/j.jcte. 2020.100238.
94. Duke DC, Barry S, Wagner DV, Speight J, Choudhary P, Harris MA. Distal technologies and type 1 diabetes management. Lancet Diabetes Endocrinol. 2018;6:143-56. https://doi.org/10. 1016/S2213-8587(17)30260-7.

95. Lim ST, Yap F, Chin X. Clinical observations bridging the needs of adolescent diabetes care during COVID-19: a nurse-led telehealth initiative. J Adolesc Health. 2020;67:615-7. https://doi. org/10.1016/j.jadohealth.2020.07.012.

96. Wan W, Nathan AG, Reza Skandari M, Zarei P, Reid MW, Raymond JK, et al. Cost-effectiveness of shared telemedicine appointments in young adults with T1D: CoyoT1 trial. Diabetes Care. 2019;42:1589-92. https://doi.org/10.2337/dc19-0363.

Publisher's Note Springer Nature remains neutral with regard to jurisdictional claims in published maps and institutional affiliations. 